\title{
UNCOMMON LOCATION OF PYOGENIC GRANULOMA IN A CHILD - CASE REPORT AND MINI-REVIEW
}

\author{
Raluca T. TATAR ${ }^{1,2} \bowtie$, Doina I. NACEA ${ }^{2}$, Dan M. ENESCU ${ }^{1,2}$ \\ 1 "Carol Davila" University of Medicine and Pharmacy, Bucharest, Romania \\ 2 "Grigore Alexandrescu" Clinical Emergency Hospital for Children, Bucharest, Romania
}

Received 24 Oct 2020, Accepted 15 Nov 2020

https://doi.org/10.31688/ABMU.2020.55.4.18

\begin{abstract}
Introduction. Pyogenic granuloma (PG) is a vascular inflammatory hyperplasia involving the skin and oral mucosa, often associated with local irritation or trauma, or with pregnancy. Intraoral location usually affects the gingiva, but tumoral aspect can be misleading, especially in extra-gingival locations. A thorough assessment and diagnosis are therefore important for ensuring the proper treatment.
\end{abstract}

Case presentation. We report the case of a 12-year-old boy who presented for a growing and bleeding tumour of his lower lip mucosa. The tumour was labeled as "hemangioma". It was growing for several weeks and associated with minor, but repeated mucosal trauma. Although the anatomic location was not common, the patient history suggested a diagnosis of PG. After a dermatologic assessment, which proposed a differential diagnosis with oral papilloma, a soft tissue ultrasound sustained the clinical diagnosis. The tumour was surgically excised and the defect was closed directly with absorbable sutures. Three weeks later the mucosa had a healthy appearance, without signs of impaired healing or tumour recurrence. The histopathological exam confirmed the clinical diagnosis.

Conclusions. There are several types of soft tissue solid or vascular tumours that can be mislabeled and

\section{Résumé}

Localisation peu fréquente du granulome pyogène dans l'enfance - cas clinique et mini-revue

Introduction. Le granulome pyogène (GP) est une hyperplasie inflammatoire vasculaire qui affecte la peau et la muqueuse buccale, souvent associée à une irritation ou un traumatisme local, ou à une grossesse. La localisation intra-orale affecte généralement la gencive, mais l'aspect tumoral peut être trompeur, en particulier dans les localisations extra-gingivales. Une évaluation et un diagnostic approfondis sont donc importants pour garantir un traitement approprié.

Présentation du cas. Nous présentons le cas d'un garçon de 12 ans qui est venu pour une consultation concernant la tumeur croissante et saignante de sa muqueuse de la lèvre inférieure. La tumeur a été étiquetée comme " hémangiome ". Elle se développait depuis plusieurs semaines et avait été associée à un traumatisme muqueux mineur mais répété. Bien que la localisation anatomique ne soit pas courante, les antécédents du patient suggéraient un diagnostic de GP. Après une consultation dermatologique qui proposait un diagnostic différentiel avec le papillome buccal, une échographie des tissus mous avait soutenu le diagnostic clinique. La tumeur a été excisée chirurgicalement et 
the diagnosis of hemangioma is commonly used for various vascular anomalies. In our case, the clinical aspect, together with the tumoral growing pattern and the history of repeated trauma, led us to the correct diagnosis and treatment. Surgical excision completely removes the PG and ensures rapid and esthetically convenient healing, without complication or tumour regrowth.

Keywords: pyogenic granuloma, children, oral mucosa, lower lip, surgical excision. le défaut a été fermé directement par des sutures résorbables. Trois semaines plus tard, la muqueuse avait une apparence saine, sans signes de cicatrisation altérée ou de récidive tumorale. L'examen histopathologique a confirmé le diagnostic clinique.

Conclusions. Il existe plusieurs types de tumeurs solides ou vasculaires des tissus mous qui peuvent être confondus entre elles et le diagnostic d'hémangiome est couramment utilisé pour diverses anomalies vasculaires. Dans notre cas, l'aspect clinique, associé à la croissance tumorale et aux antécédents de traumatismes répétés, nous ont conduits au diagnostic et au traitement corrects. L'excision chirurgicale supprime complètement le GP et assure une cicatrisation rapide et esthétique, sans complication ou croissance tumorale.

Mots-clés: granulome pyogène, enfant, muqueuse buccale, lèvre inférieure, excision chirurgicale.

The evolution of a PG is with rapid size increase, with more rapid growth after bleeding or minor trauma episodes ${ }^{7}$. Several triggers have been described for PG development, such as minimal trauma, local treatments, hormonal changes during pregnancy, infectious factors ${ }^{1,5,16}$. On the other hand, there are cases were PG occurred independently of any inducing factor or situation ${ }^{13}$. A spontaneous involution is theoretically possible and has been occasionally reported $^{4,9}$. However, the majority of PGs will require treatment ${ }^{17}$. On the other hand, tumoral recurrence after treatment has also been documented and reported $^{1,9}$. Depending on the tumour location and history, the differential diagnosis must consider several vascular, dermatologic and neoplastic conditions that may resemble with a PG: infantile hemangioma (IH), spitz naevus, common warts, amelanotic melanoma, schwannoma, squamous cell carcinoma, spindle cell tumors etc ${ }^{7,9,10}$.

Among the multiple treatment options that have been used for PGs, surgical excision proved to be the standard procedure, with less recurrence? ${ }^{9}$ When it is associated with another therapy (shave excision and electrocautery or laser treatment) some researchers described better results ${ }^{1,17}$. Other modalities are the use of various lasers, cryotherapy with liquid nitrogen and topical creams ${ }^{4,18}$. The accurate diagnosis is established for those cases where a resection specimen may be assessed by an experienced pathologist, who can describe a microscopic aspect of marked vascular proliferation, associated with the presence of granulation tissue, and sometimes, for chronic lesions, with 

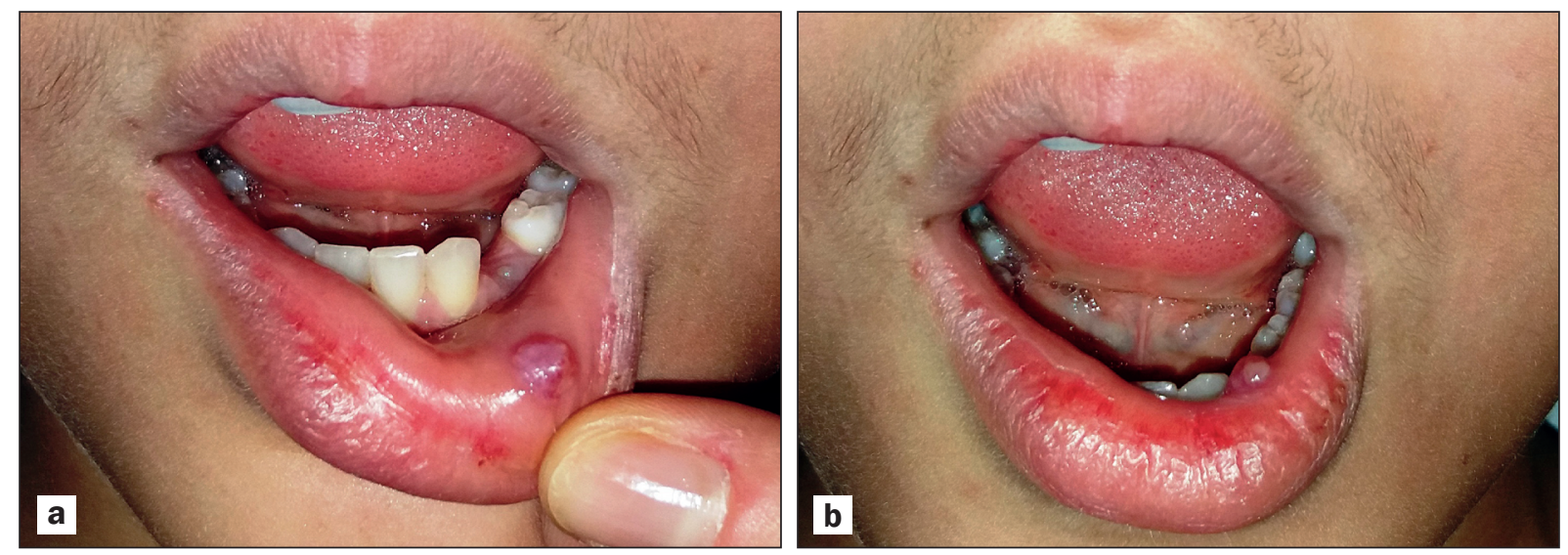

Fig. 1 a, b. Tumoral aspect at presentation
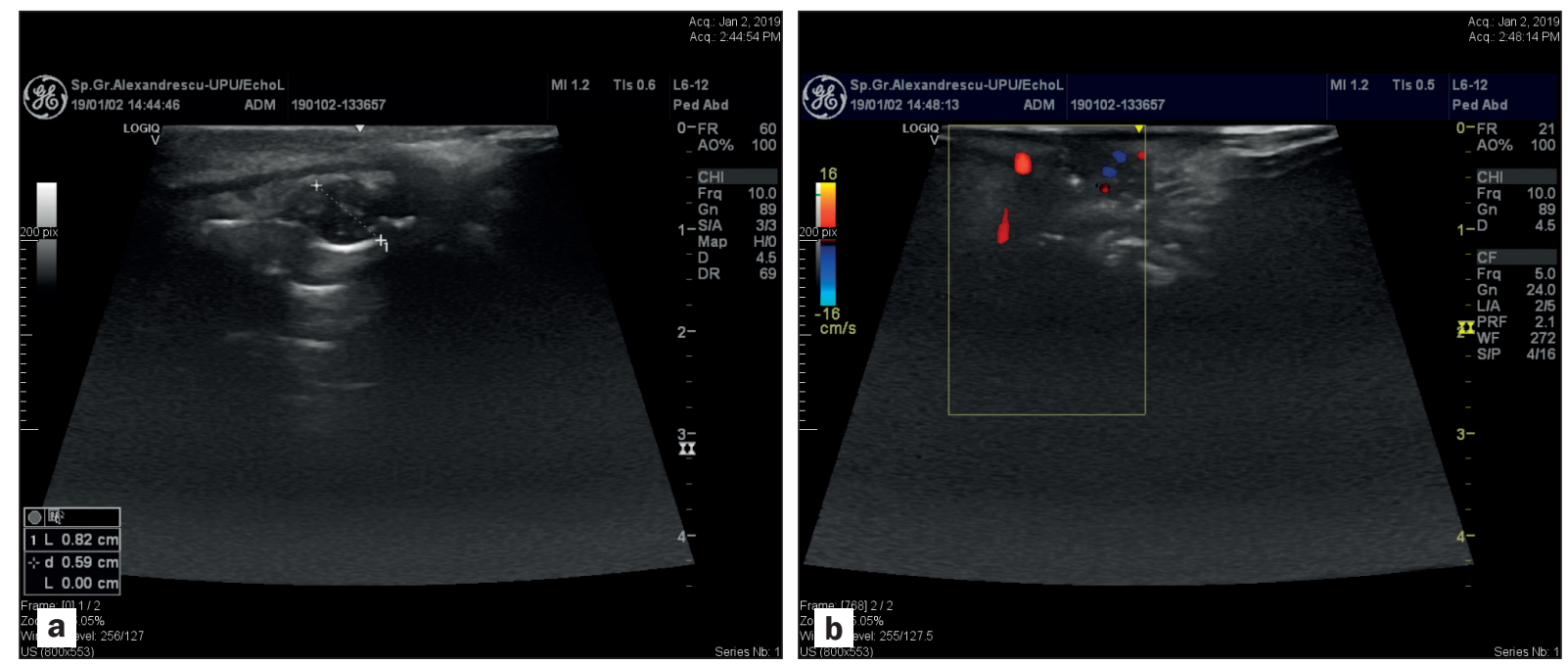

Fig. 2 a, b. Ultrasound examination of the tumour, revealing a rapid flow lesion.

inflammatory infiltrate and fibrin deposits or fibrotic tissue $^{5}$.

Since it is obvious that thorough assessment and diagnosis are important for ensuring the proper treatment for PG, this paper aims to highlight particularities of oral mucosa PG in childhood and the differential diagnosis challenge, presenting a case with unusual location, and then reviewing treatment options and outcomes based on the available literature.

\section{Case report}

We present the case of an 12-year-old boy who presented to our Plastic Surgery Department for a bleeding nodule of his lower lip mucosa (Fig. 1a,b). It was noticed during dental procedures and labeled as "hemangioma", it was growing for several weeks and it had several bleeding episodes. Both the parents and the child described a behavioral pattern of nail biting and inner lip self-biting, the latter accentuated after tumoral onset. We could therefore assume that tumoral onset was apparently associated with minor, but repeated mucosal trauma.

At examination, the tumour measured about 1 $\mathrm{cm}$ in diameter, elevated from the oral mucosal plane with approximately $3 \mathrm{~mm}$. It had a sessile aspect with smooth surface, firm consistency. The color was the same as the surrounding healthy tissue, with some fibrin deposits, the result of previous bleeding and wound healing episodes. The patient did not report any local pain before presentation or during examination.

Although the tumoral location was not common, the patient history and the clinical appearance suggested a diagnosis of pyogenic granuloma. In order to have a second opinion with regard to the nature of the lesion, the patient was sent for a dermatologic assessment, which accepted the hypothesis of an oral labial mucosa PG, but also proposed a differential diagnosis with oral papilloma. For both situations, surgical excision was the recommended course of treatment. 

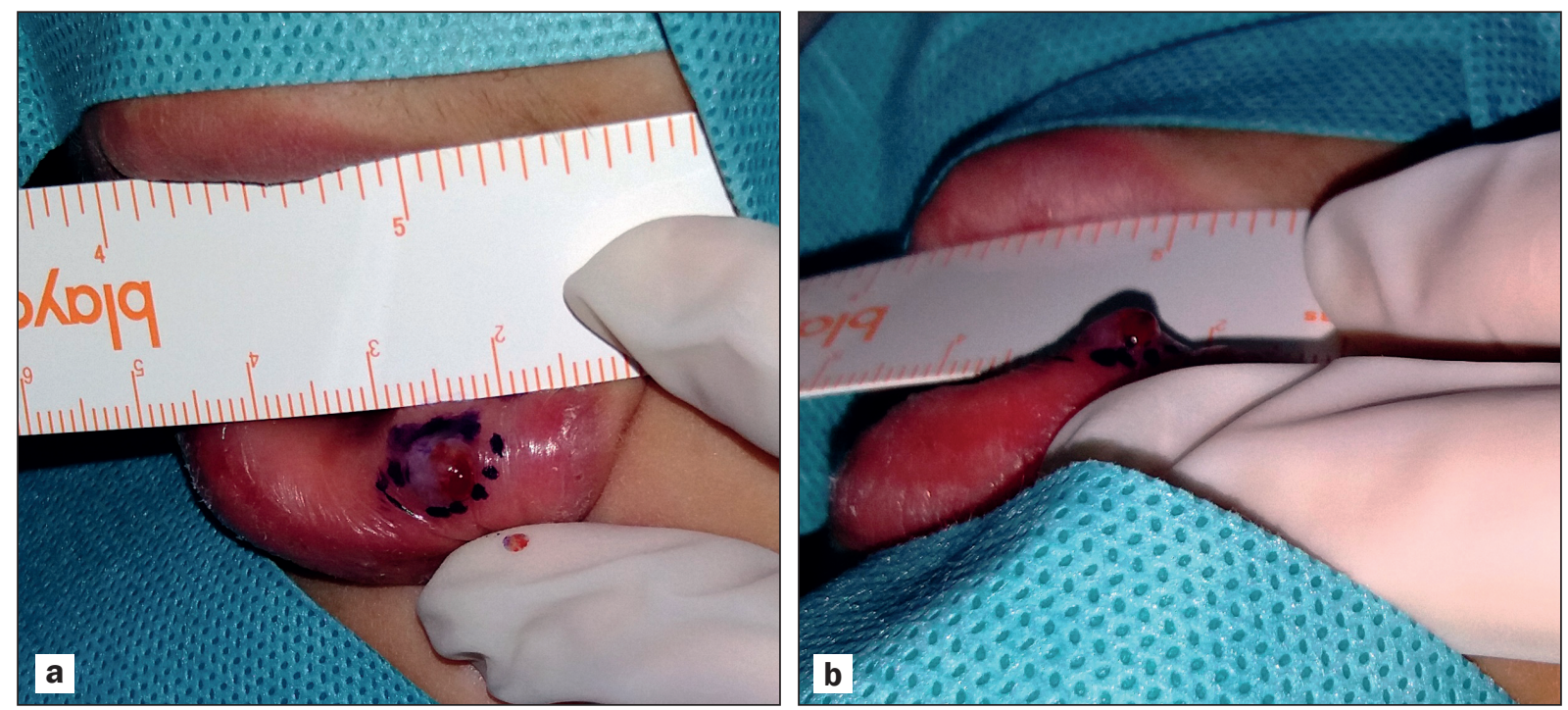

Fig. 3 a, b. Preoperative marking of landmarks
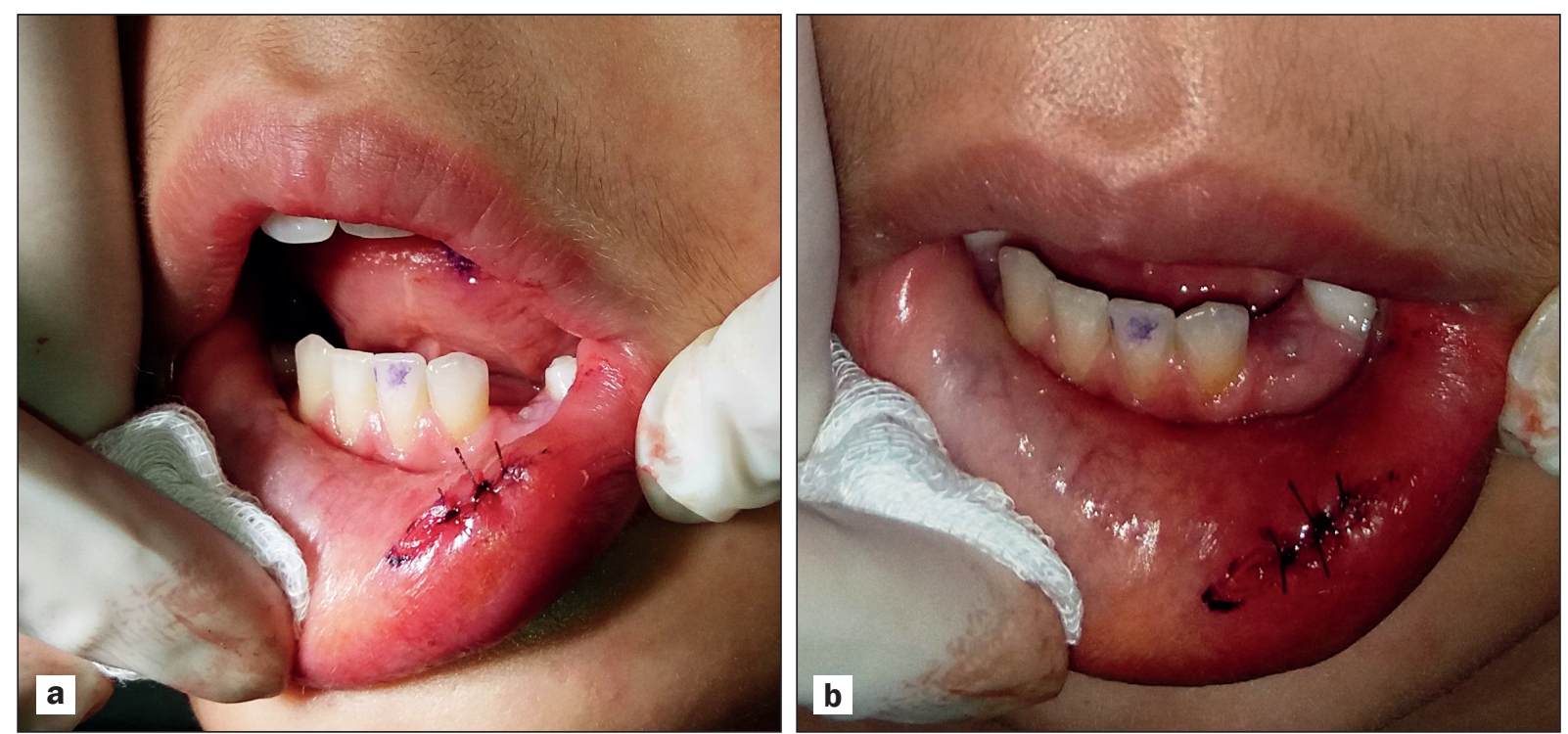

Fig. 4 a, b. Immediate postoperative aspect

At this point, the patient was admitted to our department. A blood workup was performed, that did not show any abnormalities; the complete blood count and blood coagulations tests were within the normal range values. Subsequently, a soft tissue ultrasound was carried out, revealing features consistent with a vascular tumour (rapid flow lesion) (Fig. 2a, b). We therefore established the clinical diagnosis of mucosal pyogenic granuloma. Considering the anatomical location of the tumour and the patient's age, it was surgically removed under general anesthesia, by elliptic incision and wedge-like excision (Fig. 3a, b). The defect was closed directly with absorbable sutures (Fig. 4a, b). Prophylactic antibiotics were administered after the surgery, together with mild analgesics. The postoperative evolution was favorable, without complications, no signs of active bleeding or wound infection. As per clinic protocol, the patient was discharged the next day after surgery, with strict indications and recommendations regarding oral hygiene and dietary regime, being advised to use only fluids and semisolid food for a week. The histopathological exam of the excised tumour finally confirmed the clinical diagnosis of PG, by showing highly vascular proliferation resembling with the granulation tissue, with lobular arrangement (Fig. 5).

Three weeks after surgery, the mucosa had a healthy appearance (Fig. 6), without signs of impaired healing or of tumour recurrence. An eight-month follow-up visit did not show any other changes. 

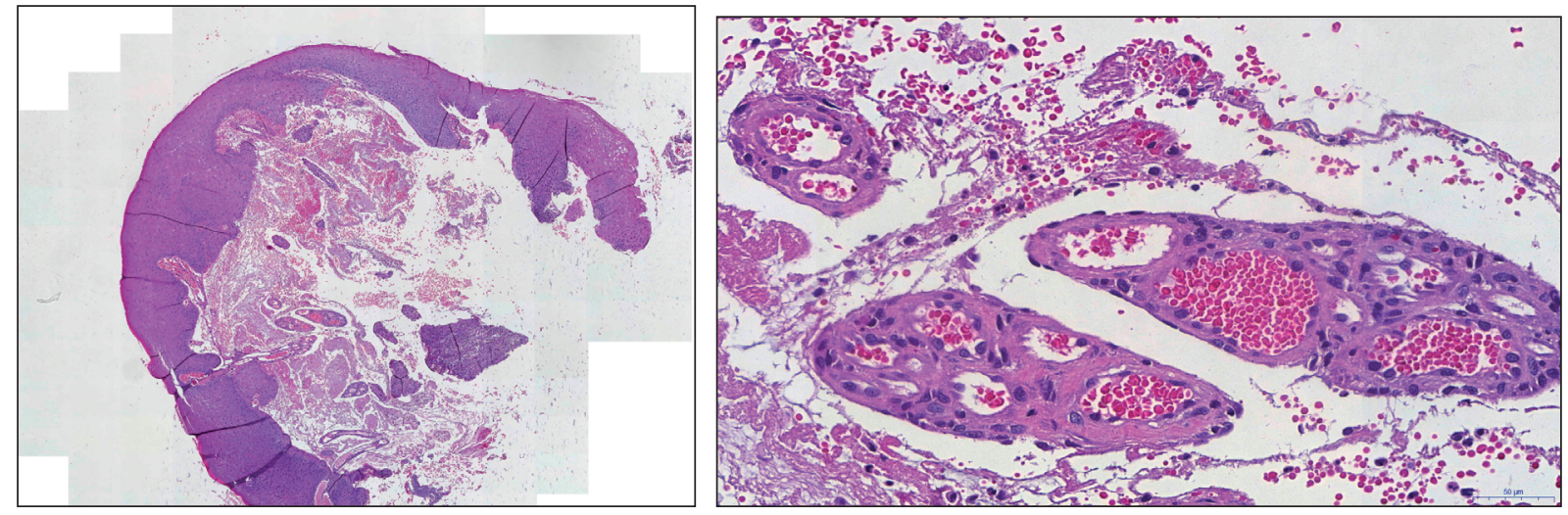

Fig. 5. Histopathological view of the tumour, at magnification $3 \mathrm{x}$ and $32.5 \mathrm{x}$ (numerous channels engorged with red blood cells, lined by plump endothelial cells)

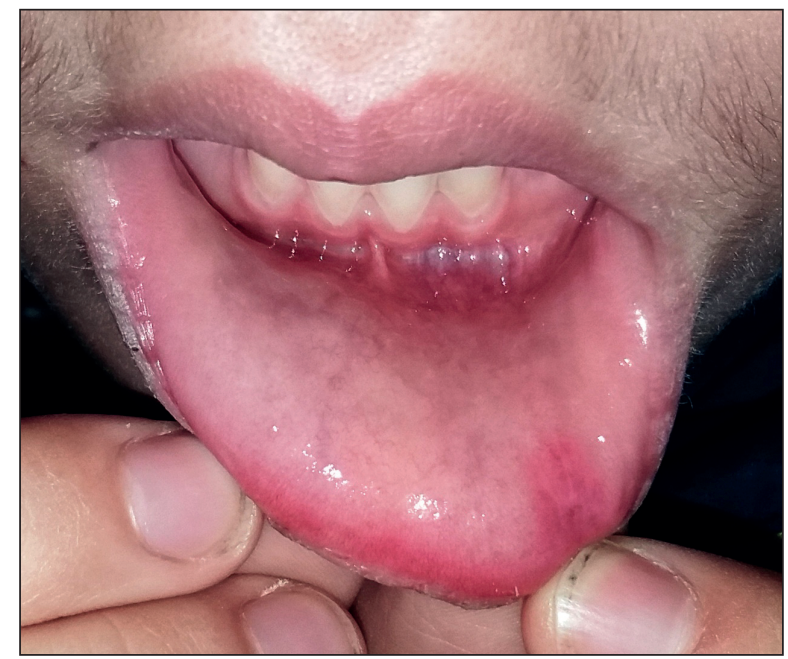

Fig. 6. Patient's aspect three weeks after surgery, good healing and no signs of recurrence

\section{Discussion}

Since it was first mentioned in the medical literature, the PG was a source of misleading descriptions. Called "botryomycome" by French surgeons and dermatologists ${ }^{18,19}$, it later became "granuloma pyogenicum" - according to Latin terminology, despite the fact that it had nothing to do with an infectious disease accumulating pus, nor with a true granuloma. The correct characterization of $\mathrm{PG}$ is as a reactive hyperplastic lesion, an acquired benign vascular tumour ${ }^{2,9}$.

Our patient was first diagnosed and referred to us for a hemangioma, one of the most common mislabels. Although it is true that both PG and infantile hemangioma (IH) are vascular tumours, according to the latest accepted International Society for the Study of Vascular Anomalies (ISSVA) classification ${ }^{20}$, their history, evolution and treatment differ significantly. They share sometimes the bright red color for superficial skin location and a predilection for the head and neck. At the same time, $\mathrm{IH}$ are more frequent in female patients and have an unique developmental pattern, becoming visible in the first month of life, growing rapidly in the following months, usually up to the age of 1 year, and then start a slow involution that will end in the late childhood ${ }^{21,22}$. Unlike IHs, a PG may occur at any point during childhood, especially around 10 years old ${ }^{1,9}$, more frequently in boys and it appears even in previously healthy adults ${ }^{11}$. Unfortunately, the incorrect use of vascular anomalies terminology has been documented ${ }^{23}$ and things do not seem to improve ${ }^{24}$, as many hemangioma-like tumours are simply diagnosed as $\mathrm{IH}^{25}$ and subsequently receive an inappropriate treatment. Therefore, every specialist dealing with these tumours (general practitioners, dermatologists, plastic surgeons, pathologists etc.) should assess them thoroughly, use the right classification and make an accurate differential diagnosis. The final separation can be done after the excision, because $\mathrm{IH}$ are the only vascular tumour positive for the GLUT-1 receptor ${ }^{3,21,22}$. The microscopic description of PG as "lobular capillary hemangioma" is another cause of confusion between the two pathologic conditions, especially because an outdated terminology used to classify IHs as capillary (actual term - superficial IH) and cavernous (actual term - deep IH). The ISSVA experts suggest that a better option would be to define PG as "lobular capillary/endothelial hyperplasia"

Besides the initial assessment as $\mathrm{IH}$, there were some other misleading aspects of this case. First, it was the tumour location on the lower lip mucosa, since oral pyogenic granulomas are commonly located on the gingiva ${ }^{8}$, as it was described by case reports ${ }^{26}$ and also by studies carried out on larger cohorts ${ }^{14,27,28}$. Extra-gingival locations are rare, and PGs on the lips are more commonly located on the outer part, namely the vermilion ${ }^{5,29,20}$. The upper or lower lip mucosa is an uncommon location, with few other reported 
cases $^{31}$, usually in adults ${ }^{15}$. Second, the sessile form was also less common, the majority of cutaneous PG presenting as pedunculated tumors. However, for physicians familiarized with PG, the fact the oral locations occur as sessile nodules should be a known fact $^{2,14}$.

The etiology of PG is not clarified. It has been described as a reactive process with inflammatory hyperplasia, hormonal imbalance, but also with a spontaneous onset, as it happens with true neoplasms ${ }^{32}$. Some researchers demonstrated the existence of a specific genetic profile associated with this tumour, but they concluded that this cannot be extended to all the cases presenting with $\mathrm{PG}^{13}$. Other studies hypothesized an impaired wound healing respons $\mathrm{e}^{25}$. Independently of the cause, the patients with PGs seek medical advice usually when they start having one or more complications: accelerated growth, impressive bleeding after minor injuries ${ }^{12,33}$, ulceration, sometimes local infection, or, something specific for oral locations, especially the labial mucosa, impaired dental occlusion ${ }^{6,31}$. Our patient's complaints were the tumoral growth and occasional minor hemorrhage. Pain is not an accompanying symptom for $\mathrm{PGs}^{27}$.

The first diagnosis is usually based on the tumoral clinical features, associated with a history of increasing size and repeated bleeding episodes, related or not with small local trauma ${ }^{1,9,12}$. The correlation with a local injury is not always possible; however, in our patient a history of self-biting was described, and it was also reported in other cases ${ }^{34}$. Almost every bleeding episode is associated to further tumoral growth. Unusual presentations, as it was also our case, may lead to inappropriate diagnosis. They need to be thoroughly investigated in order to rule out other similar conditions $s^{35}$, benign or malignant tumours ${ }^{8}$. For establishing the correct diagnosis and the extent of the surgical excision, the best approach is always within a multidisciplinary team, including a plastic surgeon, a dermatologist, a radiologist and finally a pathologist who confirms the clinical diagnosis or describes a different pathological condition ${ }^{6,9,36}$.

Once the diagnosis has been established, there are several treatment options. Surgical removal is definitely the fastest, and it ensures rapid tumour resolution and healing, no further local bleeding and absence of regrowth in most cases 9 . It can be achieved with local anesthesia, but general anesthesia may sometimes be a better option, depending upon tumour location and patient's age. PG recurrence after surgical excision has been reported ${ }^{17,37}$, but it is usually associated with an incomplete excision, caused by the choice of certain surgical technique (shave excision), by the desire of leaving a small scar, or by tumours that have a location with difficult surgical approach $^{38}$. Actually, patients are accepting the idea of a small scar instead of a tumour, even in more visible areas, and postsurgical scarring is not an issue in mucosal locations, and thus the complete removal remains the standard treatment option ${ }^{1,9,39}$. In some cases, the best solution may be a combination of methods, like associating one type of laser therapy together with the surgery ${ }^{40}$. For other cases, especially when the PG are located at the extremities (fingers and toes), surgical removal is not the first choice, because it would potentially leave a skin defect that could not be closed by direct suture, requiring a skin graft or a flap. In such circumstances, the use of lasers (Nd:YAG ${ }^{18}$, Er:YAG ${ }^{41}$, diode ${ }^{38}, \mathrm{CO}_{2}{ }^{42}$, flash lamp pulse dye laser ${ }^{43}$ etc.) despite of requiring longer time until final results and sometimes more than one session of therapy, represents a reliable option. For these cases, an early assessment by an experienced physician may ensure a proper treatment before the tumour reaches bigger sizes ${ }^{4,18}$. Other conservative therapies have been used over the time: cryosurger $\mathrm{y}^{44}$, sclerosing agents ${ }^{45,46}$, local applications of trichloroacetic acid ${ }^{47}, 5$-aminolevulinic acid ${ }^{48}$, corticosteroids $\mathrm{s}^{49}$, imiquimod ${ }^{50,51}$ and, more recently local beta blockers (timolol ${ }^{52}$ or propranolol ${ }^{53,54}$ ), those last options inspired by the results obtained in the use of these agents for $\mathrm{IH}$. Not all the treated patients responded to those treatment options, that additionally have the disadvantage of long duration, up to several months.

\section{Conclusions}

There are several types of soft tissue solid or vascular tumours that can be mislabeled between them and the diagnosis of IH is too often used for all kind of vascular anomalies, including for PGs. The multidisciplinary approach is the correct choice to rule out an alternative pathological condition and establish the right course of treatment. In our case, despite of not being placed on the gingiva or on the facial skin, the clinical aspect, together with the tumoral growing pattern and the history of repeated trauma, led us to the correct diagnosis and treatment. Surgical excision completely removes the pyogenic granuloma and ensures rapid and esthetically convenient healing, without complication or tumour regrowth, and should be the treatment of choice for PG, moreover when they are located on mucosal membranes.

\section{Author Contributions:}

R.T. was responsible for the diagnostic procedures, clinical diagnosis, and treatment decisions. R.T. and I.N. performed the surgery. R.T. wrote the manuscript. 
D.E.- Supervision. All authors contributed to the critical revision of the manuscript for valuable intellectual content. All authors have read and agreed to the published version of the manuscript.

\section{Compliance with Ethics Requirements:}

„The authors declare no conflict of interest regarding this article"

„The authors declare that all the procedures and experiments of this study respect the ethical standards in the Helsinki Declaration of 1975, as revised in 2008(5), as well as the national law. Informed consent was obtained from the patient included in the study"

"No funding for this study"

\section{Acknowledgements:}

None

\section{References}

1. Pagliai KA, Cohen BA. Pyogenic granuloma in children. Pediatric Dermatology. 2004;21: 10-13.

2. Mulliken JB. Natural history of hemangiomas, in Mulliken \& Young's Vascular Anomalies, Hemangiomas and Malformations, 2nd edition, Oxford University Press 2013, 68-110.

3. Hoeger PH, Colmenero I. Vascular tumours in infants. Part I benign vascular tumours other than infantile haemangioma. British Journal of Dermatology. 2014;171(3):466-473.

4. Dong J, Peng SG, Zhang XY, et al. Efficacy of Nd-YAG laser for treatment of pyogenic granuloma on the fingers and toes. Lasers in Medical Science. 2019;34(1):41-45.

5. Gonçales ES, Damante JH, Fischer Rubira CM, Taveira LA. Pyogenic granuloma on the upper lip: an unusual location. Journal of Applied Oral Science. 2010;18(5):538-41.

6. Gomes SR, Shakir QJ, Thaker PV, Tavadia JK. Pyogenic granuloma of the gingiva: A misnomer? - A case report and review of literature. Journal of Indian Society of Periodontology. 2013;17(4):514-9.

7. Mortazavi H, Safi Y, Baharvand M, Rahmani S, Jafari S. Peripheral exophytic oral lesions: a clinical decision tree. International Journal of Dentistry. 2017;2017:9193831.

8. Sarwal P, Lapumnuaypol K. Pyogenic granuloma. In: StatPearls [Internet]. Treasure Island (FL): StatPearls Publishing. Available at https://pubmed.ncbi.nlm.nih.gov/32310537/ (accessed 24 Oct 2020)

9. Giblin AV, Clover AJ, Athanassopoulos A, Budny PG. Pyogenic granuloma - the quest for optimum treatment: audit of treatment of 408 cases. Journal of Plastic, Reconstructive E Aesthetic Surgery. 2007;60(9):1030-5.

10. Kamal R, Dahiya P, Puri A. Oral pyogenic granuloma: Various concepts of etiopathogenesis. Journal of Oral and Maxillofacial Pathology. 2012;16(1):79-82

11. Jafarzadeh H, Sanatkhani M, Mohtasham N. Oral pyogenic granuloma: a review. Journal of Oral Science. 2006;48(4):167175 .

12. Kamala AK, Ashok L, Sujatha GP. Pyogenic granuloma on the upper labial mucosa: a case report. Journal of Clinical and Diagnostic Research. 2013;7(6):1244-6.
13. Groesser L, Peterhof E, Evert M, Landthaler M, Berneburg M, Hafner C. BRAF and RAS mutations in sporadic and secondary pyogenic granuloma. Journal of Investigative Dermatology. 2016;136(2):481-6.

14. Gordón-Núñez MA, de Vasconcelos Carvalho M, Benevenuto TG, Lopes MF, Silva LM, Galvão HC. Oral pyogenic granuloma: a retrospective analysis of 293 cases in a Brazilian population. Journal of Oral and Maxillofacial Surgery. 2010;68(9):2185-8.

15. Asha V, Dhanya M, Patil BA, Revanna G. An unusual presentation of pyogenic granuloma of the lower lip. Contemporary Clinical Dentistry. 2014;5(4):524-526.

16. Sharma S, Chandra S, Gupta S, Srivastava S. Heterogeneous conceptualization of etiopathogenesis: Oral pyogenic granuloma. National Journal of Maxillofacial Surgery. 2019;10(1):3-7.

17. Lee J, Sinno H, Tahiri Y, Gilardino MS. Treatment options for cutaneous pyogenic granulomas: a review. Journal of Plastic, Reconstructive $\mathcal{E}$ Aesthetic Surgery. 2011;64(9):1216-20

18. Yadav RK, Verma UP, Tiwari R. Non-invasive treatment of pyogenic granuloma by using Nd:YAG laser. BMJ Case Reports. 2018;2018:bcr-2017-223536.

19. Enjolras O, Mulliken JB, Kozakewich H. Vascular tumors and tumor like lesions. In Mulliken \& Young's Vascular Anomalies, Hemangiomas and Malformations, 2nd edition, Oxford University Press 2013, 259-324.

20. Wassef M, Blei F, Adams D, et al; ISSVA Board and Scientific Committee. Vascular anomalies classification: recommendations from the International Society for the Study of Vascular Anomalies. Pediatrics. 2015;136(1):e203-14.

21. Greene AK, Mulliken JB. Vascular anomalies. In Rodriguez ED, Losee JE, Neligan PC (eds). Nelligan's Plastic Surgery, vol. 3, 4th edition, Elsevier 2017, 866-887.e3.

22. Léauté-Labrèze C, Harper JI, Hoeger PH. Infantile haemangioma. Lancet. 2017;390(10089):85-94

23. Hassanein AH, Mulliken JB, Fishman SJ, Greene AK. Evaluation of terminology for vascular anomalies in current literature. Plastic and Reconstructive Surgery. 2011;127(1):34751.

24. Pahl KS, Kim K, Sams C, Alvarez H, Smith SV, Blatt J. Inconsistency in classifying vascular anomalies: What's in a name? Pediatric Blood E⿱ Cancer. 2017;65(3) e26836.

25. Godfraind C, Calicchio M, Kozakewich H. Pyogenic granuloma, an impaired wound healing process, linked to vascular growth driven by FLT4 and the nitric oxide pathway. Modern Pathology. 2013;26:247-255.

26. Peters SM, Koslovsky DA, Yoon AJ, Philipone EM. Pyogenic granuloma in the tongue in a five year old: a case report. Journal of Clinical Pediatric Dentistry. 2018;42(5):383-385.

27. Saravana G. Oral pyogenic granuloma: a review of 137 cases. British Journal of Oral and Maxillofacial Surgery. 2009;47(4):318-9.

28. Krishnapillai R, Punnoose K, Angadi PV, Koneru A. Oral pyogenic granuloma-a review of 215 cases in a South Indian Teaching Hospital, Karnataka, over a period of 20 years. Oral \& Maxillofacial Surgery. 2012;16(3):305-9.

29. Poudel P, Chaurasia N, Marla V, Srii R. Pyogenic granuloma of the upper lip: A common lesion in an uncommon location. Journal of Taibah University Medical Sciences. 2018;14(1):95-98.

30. Canivell-Zabaleta M, Martin-Lozano G, Olmos-Juarez E, Fontillon-Alberdi M, Infante-Cossio P. Extragingival pregnancy pyogenic granuloma on the lip. Journal of Craniofacial Surgery. 2018;29(1):e49-e50.

31. Banjar, A, Abdrabuh, A, Al-Habshi, M, Parambil, M, Bastos, P, Abed, H. Labial pyogenic granuloma related to trauma: a 
case report and mini-review. Dental Traumatology. 2020; 36: 446-451.

32. Lopez Gutierrez JC. Classification of vascular tumors. In Matassi R, Loose DA, Vaghi M. (eds.) Hemangiomas and Vascular Malformations, Springer Verlag Italia 2015, 59-65.

33. Wollina U, Langner D, França K, et al. Pyogenic granuloma - a common benign vascular tumour with variable clinical presentation: new findings and treatment options. Open Access Macedonian Journal of Medical Sciences. 2017; 5(4):423-426.

34. Mulinari-Santos G, Garci a BT, Taveira LA. Pyogenic granuloma on the upper lip: a rare location. Journal of Craniofacial Surgery. 2017; 28(2):577-578.

35. Ravi V, Jacob M, Sivakumar A, Saravanan S, Priya K. Pyogenic granuloma of labial mucosa: a misnomer in an anomalous site. Journal of Pharmacy and Bioallied Sciences. 2012;4(Suppl 2):S194-6.

36. Gudi SS, Sikkerimath BC, Puranik RS, Kasbe SS. Swelling on lower lip...not always a mucocele! Annals of Maxillofacial Surgery. 2013;3(1):98-99.

37. Daif ET. Correlation of age, sex, and location with recurrence of oral giant pyogenic granuloma after surgical excision. Journal of Craniofacial Surgery. 2016;27(5):e433-5.

38. Asnaashari M, Jamile Bigom-Taheri J, Mehdipoor M, Bakhshi M, Azari-Marhabi S. Posthaste outgrow of lip pyogenic granuloma after diode laser removal. Journal of Lasers in Medical Sciences. 2014;5(2):92-5.

39. Sharma S, Chandra S, Gupta S, Srivastava S. Heterogeneous conceptualization of etiopathogenesis: Oral pyogenic granuloma. National Journal of Maxillofacial Surgery. 2019;10(1):3-7.

40. Kirschner RE, Low DW. Treatment of pyogenic granuloma by shave excision and laser photocoagulation. Plastic and Reconstructive Surgery. 1999;104:1346e9.

41. Fekrazad R, Nokhbatolfoghahaei H, Khoei F, Kalhori KA. Pyogenic granuloma: surgical treatment with Er:YAG laser. Journal of Lasers in Medical Sciences. 2014;5(4):199-205.

42. Truschnegg A, Acham S, Kqiku L, Beham A, Jakse N. CO2 laser excision of a pyogenic granuloma associated with dental implants: a case report and review of the literature. Photomedicine and Laser Surgery. 2016;34(9):425-31.
43. Tay YK, Weston WL, Morelli JG. Treatment of pyogenic granuloma in children with the flashlamp-pumped pulsed dye laser. Pediatrics. 1997;99(3):368-70.

44. Ishida CE, Ramos-e-Silva M. Cryosurgery in oral lesions. International Journal of Dermatology. 1998;37(4):283-5.

45. Matsumoto K, Nakanishi H, Seike T, Koizumi Y, Mihara K, Kubo Y. Treatment of pyogenic granuloma with a sclerosing agent. Dermatologic Surgery. 200;27(6):521-3.

46. Ichimiya M, Yoshikawa Y, Hamamoto Y, Muto M. Successful treatment of pyogenic granuloma with injection of absolute ethanol. Journal of Dermatology. 2004;31(4):342-4.

47. Chiriac A, Birsan C, Podoleanu C, Moldovan C, Brzezinski P, Stolnicu S. Noninvasive treatment of pyogenic granulomas in young children with topical timolol and trichloroacetic acid. Journal of Pediatrics. 2016;169:322-322.e1.

48. Liu J, Zhou BR, Yi F, Wu HJ, Zhang JA, Luo D. Pyogenic granuloma in a patient with psoriasis successfully treated by 5 aminolevulinic acid photodynamic therapy: a case report. Experimental and Therapeutic Medicine. 2016; 11(1):345-347.

49. Parisi E, Glick PH, Glick M. Recurrent intraoral pyogenic granuloma with satellitosis treated with corticosteroids. Oral Diseases. 2006;12(1):70-2.

50. Fallah H, Fischer G, Zagarella S. Pyogenic granuloma in children: treatment with topical imiquimod. Australasian Journal of Dermatology. 2007;48(4):217-20.

51. Georgiou S, Monastirli A, Pasmatzi E, Tsambaos D. Pyogenic granuloma: complete remission under occlusive imiquimod 5\% cream. Clinical and Experimental Dermatology. 2008; 33(4):454-6.

52. Oke I, Alkharashi M, Petersen RA, Ashenberg A, Shah AS. Treatment of ocular pyogenic granuloma with topical timolol. JAMA Ophthalmology. 2017;135(4):383-385.

53. Neri I, Baraldi C, Balestri R, et al. Topical 1\% propranolol ointment with occlusion in treatment of pyogenic granulomas: an open-label study in 22 children. Pediatric Dermatology. 2018;35(1):117-120.

54. Mashiah J, Hadj-Rabia S, Slodownik D, et al. Effectiveness of topical propranolol $4 \%$ gel in the treatment of pyogenic granuloma in children. Journal of Dermatology. 2019;46(3):245-248. 